\section{MRS-I Hosts Third Annual General Meeting}

The Bangalore Local Chapter of MRS-I hosted the Third Annual General Meeting of the Materials Research Society of India at the Indian Institute of Science, Bangalore, February 9-11, 1992. The meeting was attended by 290 participants from more than 65 organizations.

In his inaugural address, C.N.R. Rao, president of MRS-I, exhorted the materials community, with his customary vigor, to accept the challenge of developing new materials for engineering purposes. $\mathrm{He}$ pointed out that physics and chemistry became materials science only when the usefulness of a property had been demonstrated. While it was important for a scientist to publish papers, he argued that it was essential to take developments to the marketplace. He stressed the role of national laboratories, such as those of CSIR, in taking developments to the marketplace.

T.R. Anantharaman, director, Thapar Corporate Research and Development Centre, Patiala, and recipient of MRS-I's Distinguished Materials Scientist of the Year Award, delivered the MRS-I honor lecture entitled "Metallic Structures: A Magnificent Obsession." Two Honorary Members of MRS-I gave special lectures. B. Ilschner of the Swiss Federal Institute of Technology, Lausanne, spoke about "Chemical and Microstructural Gradients in Solid Materials," and A. Jayaraman, Jawaharlal Nehru Centre for Advanced Scientific Research, Bangalore, highlighted "The Role of High Pressure in Materials Research." Twenty-one MRS-I Medal recipients for the year also delivered lectures.

The meeting featured three topical symposia on rapid solidification processing, advanced composites, and structural ceramics. Two poster sessions, attracting lively participation, displayed 110 poster papers covering metals and alloys; polymers; thin films; synthesis, structure, and properties; electronic materials and devices; biomaterials; composites; ceramics and glasses; and superconductivity. Best poster prizes went to six posters.

The MRSI-ICSC Superconductivity Awards were presented to S.B. Ogale, University of Poona, Pune, and J. Gopalakrishnan, Indian Institute of Science, Bangalore.

P. Rama Rao General Secretary, MRS-I

\section{MRS-I Medal Lectures 1992}

"Grains and Grain Boundaries in Electronic Materials," B.K. Das, National Physical Laboratory, New Delhi.

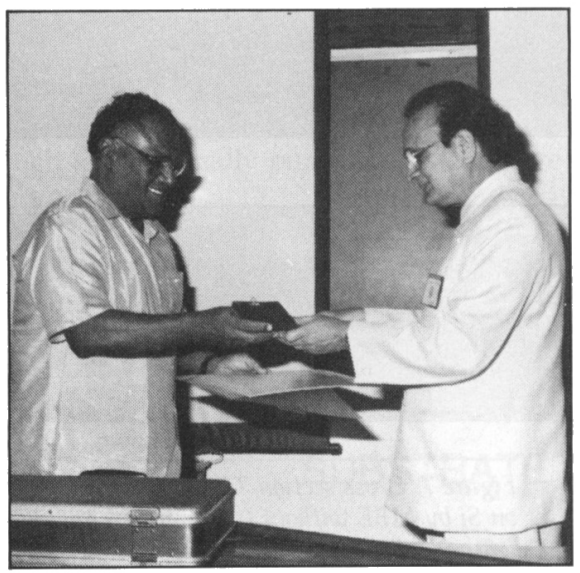

$\overline{\text { MRS-I President C.N.R. Rao (left) presents }}$ the Distinguished Materials Scientist of the Year Award to T.R. Anantharaman.

"Photoquenching of EL2 in SemiInsulating GaAs," V. Kumar, Indian Institute of Science, Bangalore.

"Technology of Bulk Synthesis and Growth of Semi-Insulating GaAs Ingots," R. Thyagarajan, Solid State Physics Laboratory, Delhi.

"Nanomaterials Synthesis," D. Chakravorty, Indian Association for the Cultivation of Science, Calcutta.

"Some Novel Approaches in Ceramics Fine Powder Processing," A.D. Damo- daran, Regional Research Laboratory, Thiruvananthapuram.

"Some Novel Chemical Reactions for HiTech Materials Preparation," P. Pramanik, Indian Institute of Technology, Kharagpur.

"Self-Organization of Dislocations and Instabilities in Plastic Flow," G. Ananthakrishna, Indian Institute of Science, Bangalore.

"Fatigue and Fracture," S. Banerjee, National Metallurgical Laboratory, Jamshedpur.

"Analytical Nondestructive Evaluation for Materials Characterization," Baldev Raj, Indira Gandhi Centre for Atomic Research, Kalpakkam.

"R\&D in Materials Science and Product Development: From Laboratory to Production," C.G. Krishnadas Nair, Hindustan Aeronautics Limited, Bangalore.

"Crystal Growth for the Present and for the Future," P. Ramasamy, Crystal Growth Centre, Madras.

"Studies on Langmuir-Blodgett Films," P. Ganguly, National Chemical Laboratory, Pune.

"Superconducting Films-Plasma Processing Techniques and Characterization," S. Mohan, Indian Institute of Science, Bangalore.

"Design of Coatings for Gas Turbine Blades," R. Sivakumar, Sree Chitra Thirunal Institute of Medical Sciences and Technology, Thiruvananthapuram.

"A Materials Science Approach to Solid Particle Erosion," G. Sundararajan, Defence Metallurgical Research Laboratory, Hyderabad.

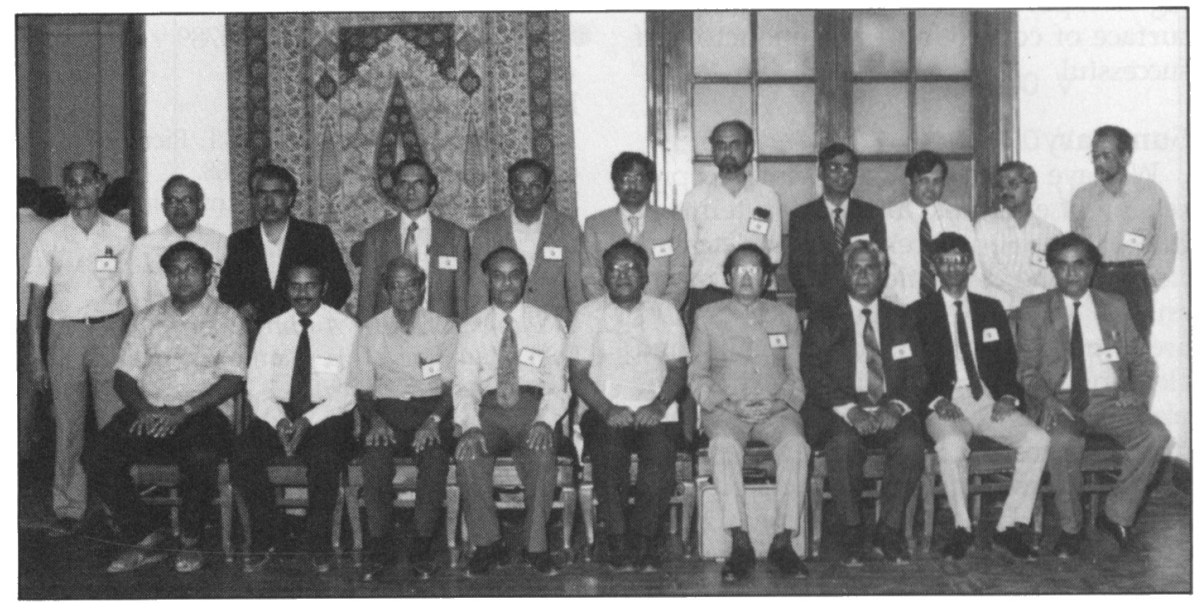

MRS-I medal winners and other honorees with MRS-I President C.N.R. Rao. Seated (left to right): G. Sundararajan, R. Sivakumar, S.R. Rajagopalan, N. Balasubramanian, C.N.R. Rao, T.R. Anantharaman, R. Thyagarajan, K.T. Jacob, Baldev Raj. Standing (left to right): G. Anan thakrishna, A.D. Damodaran, C.G. Krishnadas Nair, D. Chakravorty, P. Ramasamy, P. Pramanik, V. Kumar, B.K. Das, S.B. Ogale, Pradip, S. Banerjee. 
"Design of Crystal Structure Specific Surfactants Based on Molecular Recognition at Mineral Surfaces," Pradip, Tata Research Development \& Design Centre, Pune.

"Optical Composites," S.R. Rajagopalan, National Aeronautical Laboratory, Bangalore.

"Smart Composites," N. Balasubramanian, Eternit Everest Ltd., Bangalore.

"Al-Matrix Composites," Y.R. Mahajan, Defence Metallurgical Research Laboratory, Hyderabad.

"Sensing: Materials and Mechanisms," K.T. Jacob, Indian Institute of Science, Bangalore.

"Studies on Fuel-Clad Chemical Interactions in the FBTR," S.P. Garg, Bhabha Atomic Research Centre, Bombay.

\section{MRS-I Symposium Lectures}

\section{Symposium A-Rapid Solidification}

Processing

"Science of Rapid Solidification," P. Ramachandra Rao, Banaras Hindu University, Varanasi.

"Rapid Solidification Processing of Titanium Base Alloys," R.G. Rowe, General Electric Corporate R\&D, U.S.A.

"Rapid Solidification of Zirconium Base Alloys," G.K. Dey, Bhabha Atomic Research Centre, Bombay.

"Spray Forming--Science and Technology," S.N. Ojha, Banaras Hindu University, Varanasi.

"Nanometric Composites Through $\mathrm{RSP}_{\prime}^{\prime \prime} \mathrm{K}$. Chattopadhyay, Indian Institute of Science, Bangalore.

\section{Symposium B-Advanced Composites}

"Fiber-Reinforced Ceramic Matrix Composites," L.M. Manocha, Sardar Patel University, Vallabh Vidyanagar.

"Investigations on Hygrothermal Effects on Polymer Composites," P.K. Sinha, Indian Institute of Technology, Kharagpur.

"Aluminum Alloy Matrix Composites," B.C. Pai, R.M. Pillai, and K.G. Satyanarayana, Regional Research Laboratory, Thiruvananthapuram.

\section{Symposium C-Structural Ceramics}

"Plasma Spraying of Ceramic Powders by Sol-Gel Processing," D. Ganguly, Central Glass and Ceramic Research Institute, Calcutta, and S.V. Joshi, Defence Metallurgical Research Laboratory, Hyderabad.

"Ceramic and Metal Matrix Composites by Melt Oxidation and Infiltration," Vikram Jayaram, Indian Institute of Science, Bangalore.

"Zirconia-Toughened Ceramics," D.C. Agrawal, Indian Institute of Technology, Kanpur.

\section{E-MRS, MatTech, f.e.m.s. Join Forces for 1992 E-MRS Fall Meeting}

The European Materials Research Society's 1992 Fall Meeting, November 3 - 6 in Strasbourg, will feature the joint efforts of E-MRS, the MatTech East-West Conference organization, and the Federation of European Materials Societies (f.e.m.s.) in showcasing interdisciplinary materials R\&D in the 3rd European East-West Conference on Materials and Processes.

The first European East-West Symposium on Materials and Processes, MatTech' 90 held in Finland, was organized by the Institute of Materials Science and Technology of the Helsinki University of Technology. The Fransevitch Institute for Problems of Materials Science (Kiev, Ukraine) participated actively, as did 200 Soviet researchers. The second MatTech held in Finland in 1991 also featured strong participation by the USSR and Eastern European scientists. The third MatTech, being held as a joint venture with the 1992 E-MRS Fall Meeting, seeks to continue dialogue and technology transfer between Eastern and Western scientists.

Five symposia are planned, as is a special Exhibition and Contact Forum for EastWest Technology Transfer featuring achievements of Eastern countries in advanced materials.

\section{Abstract Deadline is August 1, 1992}

Abstracts from Western and Central countries should be submitted to the chairs identified in the following descriptions.

Abstracts from Eastern countries should be submitted to:

MatTech Centre East

c/o Frantsevich Institute for Problems of Materials Science

3 Krzhizhanovsky str.

$252142 \mathrm{Kiev}$, Ukraine

Phone (7) 44-444 2271 (V. Trefilov, chair)

(7) 44-444 2264 (V. Skorokhod, vice-chair)

(7) 44-444 1458 (A. Tchetchel, coordinating chief)

(7) 44-4440030 (S. Pan, scientific secretary) Fax (7) 44-444 0492 or (7) 44-444 2078

Telex 131257 stan su

\section{Symposium A-High Tc Superconductors}

This 31/2-day symposium will deal with thin films, single crystals, polycrystalline and textured materials (tapes, wires, thick films). Special attention will be paid to the influence of defects on the superconducting, other physical properties, and device performances. Emphasis will be placed on the following topics: defects in thin films and single crystals; grain boundaries and superconducting properties; influence of intrinsic and induced defects on the properties; influence of perfection of materials and multilayers on device performances; and applications.

Chairs: J. Dumas (Grenoble, France), H.W. Neumüller (Erlangen, Germany), and P.V. Seminozhenko (Kharkov, Ukraine).

Abstracts go to: J. Dumas, L.E.P.S.-CNRS, 25 , avenue des Martyrs, BP 166, 38042 Grenoble Cedex 9, France; phone (33) 768879 01; fax (33) 76887988.

Submit abstracts from Eastern countries to MatTech Centre East.

\section{Symposium B-Materials Under Extreme Conditions}

This 3-day symposium will emphasize three main subject areas: (1) materials at very high temperatures (plasticity and strength, mechanical and chemical stability, transport properties, surface protection, processing aspects, etc...); (2) materials at low temperatures (all aspects of mechanical, optical, and electronic properties of materials at cryogenic temperatures); and (3) materials at high deformation rates (rapid deformation in materials processing and applications) Original contributions from other areas will also be considered. Invited speakers will be selected from the submissions.

Chairs: G. Kostorz (Zürich, Switzerland) and V. Trefilov (Kiev, Ukraine).

Abstracts go to: G. Kostorz, Angewandte Physik, ETH Zürich, 8093 Zürich, Switzerland; phone (41) 137 73399; fax (41) 137 20540; telex: 823474 ehpz ch.

Submit abstracts from Eastern countries to MatTech Centre East.

\section{Symposium C-Nanophase Materials}

Nanostructured metals, semiconductors and ceramics have promising electronic, magnetic, and mechanical properties because of the effects of particle size and the high degree of disorder in the interfacial regions. The relationship between microstructure and properties has not been fully understood yet. The application of such materials will be in the field of net shape forming of brittle materials, sensors, electromagnetics shielding, magnetic materials, tribology, etc.... A series of invited lectures will report on the state of the art in the various aspects of this area of materials 